\title{
Health Care System Efficiency Analysis Of G12 Countries
}

Sam Mirmirani, (E-mail: smirmira@bryant.edu), Bryant College Matthias Lippmann, (E-mail: mll7@bryant.edu), Bryant College

\begin{abstract}
Data Envelopment analysis of the health care delivery system of G12 nations is presented here. Japan and Spain scored the highest and the US, the lowest level of relative efficiencies. Health care outputs are life expectancy and infant mortality. Inputs are per capita health care expenditure; population adjusted physicians, hospital beds, and MRI; and a proxy for the level of education. DEA tests are applied for the 1991-1995 period using both CCR and BCC models. The paper argues that the lack of universal health care coverage and a single payer system are among the problems that the United States needs to address in order to improve its health care delivery.
\end{abstract}

\subsection{Introduction}

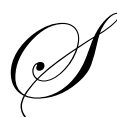

ignificant increases in health care costs have been burdening national economies for a number of years. This problem is of particular concern to industrialized countries where support for vital services, such as, national security and education are gaining more public demand. In 1984, OECD countries had a health care per capita expenditure mean of $\$ 870.00$ (with purchasing power parity adjustment); this figure rose to $\$ 1,983.00$ in 2000. When compared with the OECD means, the United States has maintained two times its per capita expenditure in the past 20 years. While controlling costs is the priority, both developed and developing nations are trying to improve access to and quality of health care services for their citizens.

The majority of research in the area of efficiency measurement has focused on the firm/organizational level. In the health care sector, as increasingly more resources are poured in, it is equally important to know the relative efficiency of the entire (macro) system. However, an important aspect of macro-level analysis is to have input and output measures that are consistent, definable and uniform across different systems.

Among the various methods of efficiency assessment, researchers in the field of business management have frequently used Data Envelopment Analysis (DEA). The robustness of DEA has been the main reason for its wide popularity. Although there are published studies related to a comparative analysis of health care systems, none, at the time of writing this paper, have applied the DEA method in assessing macro-level efficiencies.

The objective of this paper is to apply the DEA technique to the measurement of health care efficiencies of G12 countries and discuss policy implications of such findings. The organization of the paper is as follows: First, a review of literature is provided. Next, the DEA methodology is elaborated upon and is followed by empirical testing and analysis. The last part of the paper will be devoted to the summary and conclusions.

\section{Literature Review}

In a comparative analysis of health care systems, we have found a number of fairly recent studies. In a five nation (New Zealand, UK, US, Canada, and Australia) study, Blendon et. al. (2003) finds that a significant number of citizens are dissatisfied with their health care system. With a focus on OECD countries, Anell and Willis (2000) suggest that instead of expenditure measures, using a resource profile is a more desirable alternative for an international comparison of health care systems. In another OECD-based study, Anderson, et. al. (2003) suggest 
that differences in health care spending patterns between the United States and the rest of the member nations are mostly explained by higher prices in the US. With a sampling of 191 countries worldwide, Evans et al. (2001) applied the regression technique to conduct a comparative efficiency of national health care systems. Using life expectancy as health output and health expenditures and average schooling as inputs, they conclude that while increased resources result in improved health, a more efficient use of resources can also contribute to the overall health care of a nation.

As mentioned earlier, a large majority of DEA studies focus on micro-level applications; very few on macro-level applications. For example, Dimelis and Dimopoulou (2002) use DEA to evaluate the productivity growth of countries in the European Union. They suggest that because DEA does not impose any constraints, it "frees" the user from assigning a priori assumptions about weights used in the model. In another study, Cherchye (2001) applies DEA to assess macroeconomic policy performance of OECD countries. Here also, DEA's robustness and its ability to allow researchers to assess the relative rankings of the observed decision making units, (countries) are the motivation for its application.

Within the health care sector, DEA has gained much popularity in the 1990's. Hollingsworth et. al (1999) provides a thorough review of various applications. More recent applications of DEA to hospital efficiency measurement can be found in Hofmarcher et. al. (2002), Giokas (2002), and Bhat (2001) that also elaborates on its extensions, strengths and limitations. DEA's comparison with regression analysis is applied to the managed care organization by Nyhan and Cruise, (2000) and to primary care by Giuffrida and Gravelle (2001).

\section{DEA Model}

DEA is a linear programming tool that is primarily used to estimate the optimal combinations of inputs and outputs to construct an efficiency frontier. In other words, technical efficiency in DEA is characterized by the frontier (isoquant) that shows the lowest input used to achieve a given level of output. The frontier is based on actual observations from organizations, known as decision-making units (DMUs). DEA calculates the efficiency of a given system or organization relative to the best performing DMU. A DMU is considered technically inefficient if it lies below the frontier. Those on the frontier are, of course, the efficient systems.

Theoretical advantages and disadvantages of the DEA technique as compared to other techniques (for example, the regression technique) as well as a wide range of DEA applications have been summarized and evaluated by Seiford (1996) and Berger et. al. (1997). A common thread in most of the studies that have chosen DEA as their preferred method is due to its less restrictive nature. Furthermore, its ability to perform reliably, with accurate results, when a small sample of observations is present, is highlighted in Smith (1997).

The theoretical framework of DEA was first introduced in a seminal study by Charnes et. al. (1978). This study extended the single-output-input technical efficiency measure (pioneered by Farrell, 1957), to a multiple output-input relative efficiency measures. Since then, a number of variations and extensions of the original model and software development have been introduced. See, for example, Cooper, et. al. (2000) and Thanassoulis (2001).

An important consideration of the DEA model involves the scale by which a DMU is operating. If constant return to scale is assumed, the size of the DMU will not be relevant in the calculation of relative efficiency measures. In another words, a small health care system can produce an output with the same input-output ratio as a large system can. This is known as the Charnes-Cooper-Rhodes (CCR) model. However, there exists a possibility that a system will have increasing returns to scale; for example, one unit of input resulting in more than one unit of output. It is also possible to have decreasing returns to scale; for example, one unit of input resulting in less than one unit of output. Under such circumstances, an alternative/extension of DEA, known as Banker-Charnes-Cooper (BCC) model, is the appropriate method to assess relative efficiencies.

A graphical illustration of the CCR and BCC production frontiers are depicted in Figures 1 and 2. 


\section{Figure 1- Production Frontier of The CCR Model}

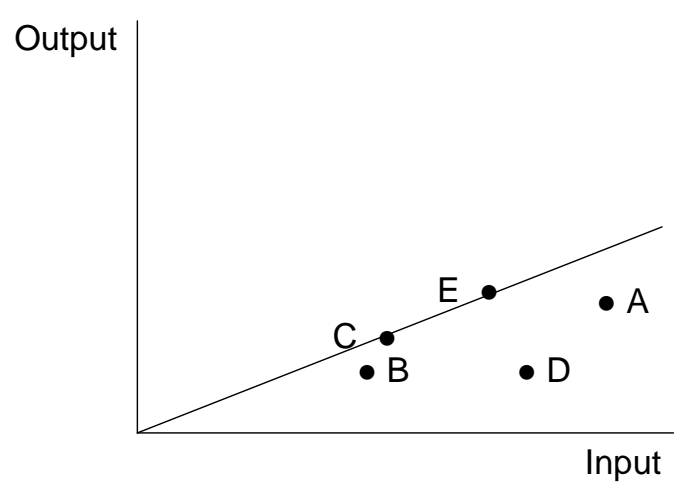

In these diagrams, for simplicity in comparison of the two models, we are showing the case for one input and one output. In each figure, the points $\mathrm{C}$, and $\mathrm{E}$ represent those DMUs that are efficient, while points $\mathrm{A}, \mathrm{B}$, and $\mathrm{D}$ are those systems that are deemed to be relatively inefficient.

\section{Figure 2- Production Frontier of The BCC Model}

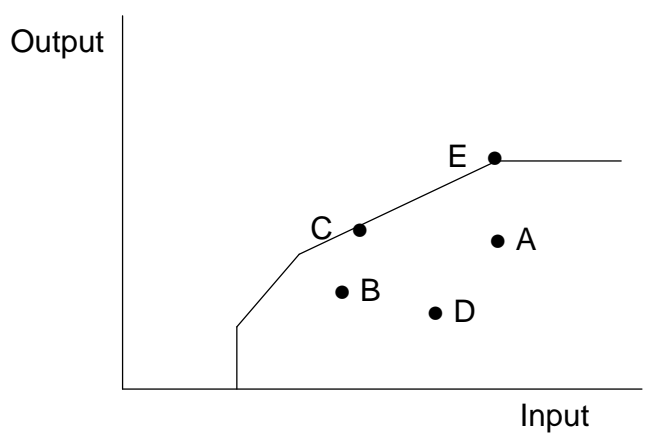

The formulation of the general DEA model is depicted below. The objective is to maximize output subject to resource constraints. There are K systems (DMUs) to compare their efficiencies, each with a set of $\mathrm{Y}$ outputs $\left(\mathrm{Y}_{\mathrm{rk}}\right)$ and a set of $\mathrm{X}$ inputs $\left(\mathrm{X}_{\mathrm{ik}}\right)$. The efficiency parameter $\left(\mathrm{E}_{\mathrm{k}}\right)$ is determined by solving a set of linear programming equations, one for each system (DMU).

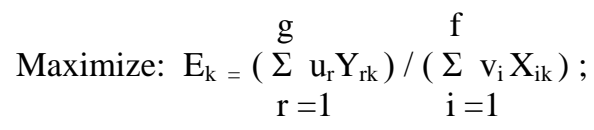

Subject to: $\quad \mathrm{E}_{\mathrm{k}} \leq 1, \mathrm{k}=1, \ldots \mathrm{n}$;

$\mathrm{u}_{\mathrm{r}} \geq 0$;

$\mathrm{v}_{\mathrm{i}} \geq 0$;

where: $\quad \mathrm{Y}_{\mathrm{rk}}$ is the rth. output from the kth. DMU;

$\mathrm{X}_{\mathrm{ik}}$ is the ith. intput used by the kth. DMU;

$\mathrm{u}$ and $\mathrm{v}$ are the weights generated from the model; $\mathrm{g}$ and $\mathrm{f}$ are the number outputs (2) and inputs (5) respectively;

$E_{k}$ is the ratio of weighted outputs to weighted inputs, the weights are selected in a way that makes $\mathrm{DMU}_{\mathrm{k}}$ as efficient as possible relative to all other DMUs. 
The basic DEA (as delineated) poses no other constraints other than the ones shown above. This provides us with the highest relative ratings within the DEA framework and thus, the user is not obligated to pre-assign relative weights. The program identifies one or a group of systems that are performing optimally. Such systems are assigned a score of "1" (one) and the rest are scored less than " 1 " (one). The efficiency frontier or "data envelope" is created on the basis of the DMU(s) that are receiving the score of "1" (one).

\section{Empirical Test and Analysis}

There are two main factors in determining the choices of variables used in the study, namely, consistency of measurement among G12 (in reality, there are thirteen members in the so call "G12") countries, and the availability of data across the board. The period of investigation is 1991-1995. The majority of data is extracted from the OECD, 2000 Report. When missing data was present, other (mainly internet) sources, were used, a list of which is attached as appendix " $A$ ".

Output variables are the average (male and female) life expectancy and infant mortality rates. As evidenced by most of the previous health care related studies, these are two commonly reported macro/national health care outcomes. For inputs, it is our intention to include variables, or, if not directly available, proxies, for financial, physical, technological and social factors that will influence health care outcomes in a nation. Therefore, those inputs that are incorporated in this study are: per capita health care expenditure in US dollar and adjusted for purchasing power parity, number of inpatient hospital beds per thousand population, number of physicians per thousand population, number of magnetic resonance imaging (MRI) per million population and the average school life expectancy.

In performing DEA, first, we focused on direct health care related inputs by omitting average school life expectancy. Both models of DEA, CCR and BCC are applied, efficiency parameters are measured and the ranking of member countries are tabulated. A country with a rank of "1" represents the most efficient and "13", the most inefficient. The results of the models are shown in Tables 1 and 2.

Table 1- Efficiency Ranking, CCR Model, Resources Only

\begin{tabular}{|c|c|c|c|c|c|c|c|c|c|}
\hline Country & \multicolumn{2}{|c|}{$\mathbf{1 9 9 1}$} & \multicolumn{2}{c|}{$\mathbf{1 9 9 3}$} & \multicolumn{2}{c|}{$\mathbf{1 9 9 5}$} & \multicolumn{3}{c|}{ Mean Rank } \\
\hline & Life & Mort. & Life & Mort. & Life & Mort. & Life & Mort. & All \\
\hline AUS & 5 & 6 & 6 & 5 & 6 & 7 & 5.7 & 6.0 & 5.8 \\
\hline BLG & 4 & 8 & 7 & 11 & 8 & 12 & 6.3 & 10.3 & 8.3 \\
\hline CAN & 11 & 9 & 11 & 12 & 10 & 11 & 10.7 & 10.7 & 10.7 \\
\hline FRA & 10 & 11 & 9 & 9 & 9 & 5 & 9.3 & 8.3 & 8.8 \\
\hline GER & 9 & 7 & 10 & 7 & 11 & 9 & 10.0 & 7.7 & 8.8 \\
\hline ITA & 7 & 10 & 5 & 8 & 3 & 6 & 5.0 & 8.0 & 6.5 \\
\hline JAP & 3 & 1 & 3 & 1 & 4 & 3 & 3.3 & 1.7 & 2.5 \\
\hline NET & 8 & 5 & 8 & 6 & 7 & 8 & 7.7 & 6.3 & 7.0 \\
\hline SPA & 1 & 2 & 1 & 2 & 1 & 1 & 1.0 & 1.7 & 1.3 \\
\hline SWD & 6 & 4 & 4 & 3 & 5 & 2 & 5.0 & 3.0 & 4.0 \\
\hline SWS & 12 & 12 & 12 & 10 & 12 & 10 & 12.0 & 10.7 & 11.3 \\
\hline GBR & 2 & 3 & 2 & 4 & 2 & 4 & 2.0 & 3.7 & 2.8 \\
\hline USA & 13 & 13 & 13 & 13 & 13 & 13 & 13.0 & 13.0 & 13.0 \\
\hline
\end{tabular}


Table 2- Efficiency Ranking, BCC Model, Resources Only

\begin{tabular}{|c|c|c|c|c|c|c|c|c|c|}
\hline Country & \multicolumn{2}{|c|}{1991} & \multicolumn{2}{c|}{$\mathbf{1 9 9 3}$} & \multicolumn{3}{c|}{1995} & \multicolumn{3}{c|}{ Mean Rank } \\
\hline & Life & Mort. & Life & Mort. & Life & Mort. & Life & Mort. & All \\
\hline AUS & 6 & 9 & 5 & 7 & 7 & 9 & 6.0 & 8.3 & 7.2 \\
\hline BLG & 11 & 12 & 11 & 12 & 11 & 12 & 11.0 & 12 & 11.5 \\
\hline CAN & 3 & 6 & 5 & 10 & 5 & 10 & 4.3 & 8.7 & 6.5 \\
\hline FRA & 9 & 10 & 7 & 9 & 7 & 4 & 7.7 & 7.7 & 7.7 \\
\hline GER & 12 & 8 & 12 & 6 & 12 & 7 & 12.0 & 7.0 & 9.5 \\
\hline ITA & 10 & 11 & 8 & 11 & 6 & 11 & 8.0 & 11.0 & 9.5 \\
\hline JAP & 1 & 1 & 1 & 1 & 1 & 3 & 1.0 & 1.7 & 1.3 \\
\hline NET & 7 & 7 & 10 & 8 & 10 & 8 & 9.0 & 7.7 & 8.3 \\
\hline SPA & 1 & 1 & 1 & 1 & 1 & 1 & 1.0 & 1.0 & 1.0 \\
\hline SWD & 4 & 4 & 3 & 3 & 3 & 1 & 3.3 & 2.7 & 3.0 \\
\hline SWS & 5 & 4 & 4 & 5 & 4 & 5 & 4.3 & 4.7 & 4.5 \\
\hline GBR & 8 & 3 & 9 & 4 & 9 & 6 & 8.7 & 4.3 & 6.5 \\
\hline USA & 12 & 13 & 13 & 13 & 13 & 13 & 12.7 & 13 & 12.8 \\
\hline
\end{tabular}

Of the thirteen nations included in this test, whether we use constant returns to scale, i.e. CCR model, or variable returns to scale, i.e. BCC model, the Untied States ranks as the least efficient system. This is the case for both life expectancy and infant mortality outcomes in each of the three years of observations, as well as the respective average rankings for the entire period. On the other hand, Spain is the most efficient and Japan is positioned in a close second rank. Beyond the top and bottom performers, there are some variations in the rankings of other nations when individual outputs (life expectancy and infant mortality) are considered and CCR and BCC results are compared. When combined mean ranking score is observed, the most pronounced change occurred for Switzerland when we switch from CCR to BCC. Switzerland moved from a rank of "11.3" to a rank of " 4.5 ". This suggests that the scale of their health care system as a whole is an important factor in determining their efficiency level. When we concentrate on life expectancy alone, Canada, Switzerland and Great Britain stand out. Focusing on Mortality rate, only Switzerland, again, shows a significant variation in its ranking.

Besides direct resources used for health care, other factors such as the level of education, are influential in the health outcomes of a nation. The OECD reports education life expectancy for its members on an annual basis. We included such a variable in the next test and the results are shown in Tables 3 and 4. Since Italy does not report the education level, the ranking order is between " 1 " and "12". Also, in 1995, the education factor was missing for Spain, thus their mean ranking is based on 1991 and 1993.

Table 3- Efficiency Ranking, CCR Model, Resources and Schooling

\begin{tabular}{|c|c|c|c|c|c|c|c|c|c|}
\hline Country & \multicolumn{2}{|c|}{$\mathbf{1 9 9 1}$} & \multicolumn{2}{c|}{$\mathbf{1 9 9 3}$} & \multicolumn{3}{c|}{$\mathbf{1 9 9 5}$} & \multicolumn{3}{c|}{ Mean Rank } \\
\hline & Life & Mort. & Life & Mort. & Life & Mort. & Life & Mort. & All \\
\hline AUS & 5 & 6 & 9 & 8 & 5 & 7 & 6.3 & 7.0 & 6.7 \\
\hline BLG & 9 & 11 & 10 & 11 & 9 & 10 & 9.3 & 10.7 & 10.0 \\
\hline CAN & 12 & 10 & 12 & 10 & 11 & 9 & 11.7 & 9.7 & 10.7 \\
\hline FRA & 8 & 9 & 8 & 9 & 6 & 5 & 7.3 & 7.7 & 7.5 \\
\hline GER & 10 & 8 & 7 & 6 & 7 & 6 & 8.0 & 6.7 & 7.3 \\
\hline JAP & 1 & 1 & 1 & 1 & 1 & 1 & 1.0 & 1.0 & 1.0 \\
\hline NET & 9 & 7 & 5 & 7 & 8 & 8 & 7.3 & 7.3 & 7.3 \\
\hline SPA & 1 & 2 & 1 & 3 & NA & NA & 1.0 & 2.5 & 1.8 \\
\hline SWD & 3 & 3 & 4 & 2 & 3 & 1 & 3.3 & 2.0 & 2.7 \\
\hline SWS & 6 & 4 & 6 & 4 & 1 & 3 & 4.3 & 3.7 & 4.0 \\
\hline GBR & 4 & 5 & 6 & 4 & 1 & 3 & 3.7 & 4.0 & 3.8 \\
\hline USA & 11 & 12 & 11 & 12 & 10 & 11 & 10.7 & 11.7 & 11.2 \\
\hline
\end{tabular}


Table 4- Efficiency Ranking, BCC Model, Resources and Schooling

\begin{tabular}{|c|c|c|c|c|c|c|c|c|c|}
\hline Country & \multicolumn{2}{|c|}{1991} & \multicolumn{2}{c|}{$\mathbf{1 9 9 3}$} & \multicolumn{2}{c|}{$\mathbf{1 9 9 5}$} & \multicolumn{3}{c|}{ Mean Rank } \\
\hline & Life & Mort. & Life & Mort. & Life & Mort. & Life & Mort. & All \\
\hline AUS & 7 & 9 & 5 & 7 & 6 & 8 & 6.0 & 8.0 & 7.0 \\
\hline BLG & 10 & 11 & 10 & 11 & 9 & 10 & 9.7 & 10.7 & 10.2 \\
\hline CAN & 5 & 6 & 5 & 10 & 5 & 9 & 5.0 & 8.3 & 6.7 \\
\hline FRA & 9 & 10 & 7 & 9 & 6 & 4 & 7.3 & 7.7 & 7.5 \\
\hline GER & 11 & 8 & 11 & 6 & 10 & 6 & 10.7 & 6.7 & 8.7 \\
\hline JAP & 1 & 1 & 1 & 1 & 1 & 1 & 1.0 & 1.0 & 1.0 \\
\hline NET & 8 & 7 & 9 & 8 & 8 & 7 & 8.3 & 7.3 & 7.8 \\
\hline SPA & 1 & 1 & 1 & 1 & NA & NA & 1.0 & 1.0 & 1.0 \\
\hline SWD & 1 & 1 & 3 & 3 & 3 & 1 & 2.3 & 1.7 & 2.0 \\
\hline SWS & 6 & 5 & 4 & 5 & 4 & 5 & 4.7 & 5.0 & 4.8 \\
\hline GBR & 1 & 1 & 8 & 4 & 1 & 1 & 3.3 & 2.0 & 2.7 \\
\hline USA & 11 & 12 & 12 & 12 & 11 & 11 & 11.3 & 11.7 & 11.5 \\
\hline
\end{tabular}

Like in previous tests, when we observe the combined mean ranking, once again, the United States maintains its position as the least efficient health care system. Spain and Japan are ranked as number one and Sweden takes the second ranked position. While concentrating on the cross variation of ranks when we switch between the two tables, we noticed that Canada and not Switzerland, stands out, as was the case in previous tests. Canada moved from a rank of "10.7" to "6.7". This move, however, was mostly attributable to the changes that occurred in their respective positions in the life expectancy outcome. One may suggest that the scale of operation in Canada's health care system [as a whole] is an important factor in determining their efficiency position in the group. Overall, the cross variation in ranking tends to be less in mortality outcome than in life expectancy.

Another finding that is not shown in the tables above, relates to the actual efficiency scores that are calculated in our test. We have found that, overall, when we switch from the CCR to BCC model, the variation in scores between the countries tend to narrow noticeably. In addition, it is revealed that within each table variation in efficiency scores, between the top and bottom ranked countries, is significantly less in BCC tests than those nations in CCR tests. For example, in Table 1 (CCR test), the efficiency score of Spain (ranked "1") in 1991 where life expectancy is equal to 1.00 and the United States (ranked "13") where life expectancy is equal 0.296. In that same category, using Table 2 (BCC test), while Spain maintains the score of 1.00, the United States, in a tie with Germany (ranked "12"), receives an efficiency score of 0.953 . These results tend to remain consistent for other years and tests.

\section{Summary and Conclusions}

While in industrialized countries, such social service provisions as education, defense, national security, social security and retirement plans, draw public attention, a significant and continuous rise in health care costs, adds more to the social and political tensions among their citizens. Reform and restructuring are among a few policy initiatives that those nations have been trying to implement as a way to control their health care industries.

Our goal, ultimately, is to add more depth to the debate over which model of heath system should be pursued. Prior to any restructuring or reform occurs, it is crucial to identify, quantitatively, those nations with the most efficient health care delivery system. Our focus is to assess health care system efficiency of G12 countries. The Data Envelopment Analysis, a linear programming technique, is the most widely used in assessing the efficiency of organizations in both private and public sectors. However, there are relatively few studies that implemented DEA in a macroeconomic environment.

An important issue when implementing DEA is the assumption related to the scale economies. For that we generated two sets of tests. One test is run with the assumption of constant returns to scale and the other with variable returns to scale. First, we centered our attention on those resources that directly influence health care 
outcomes of life expectancy and infant mortality. Then, we included a proxy for education (education life expectancy) as an indirect factor.

In comparing the ranking order of the countries, in all tests, the United States proved to be the least efficient system while Spain and Japan rankings are consistently the most efficient systems. One can argue that the inefficiencies in the United States can be explained by the fact that Americans spend significantly more on their health care than any other nation. Such expenditure is justified on the notion that Americans regard life and its quality with high value. For example, the United Sates spends proportionately more for extending life for individuals that are terminally ill, considered to be the very old, cases involving neo-natal care and premature births. This argument, although may be true, concentrates on the micro aspects of the health care deliver system and is contrary to the focus of this paper.

What lessons can the United States learn from this? The answer is certainly not a simple one. However, when we look at the variations in the overall systems among G12 members, there are some rather clear lessons for the United States. In a comparative study of four European nations (all of which are include in G12) and the United States, Brown (2003), among many aspects of health care delivery, supports the notion of universal health care coverage under a single payer system.

On the other hand, there is a long-standing theory in economics that attests to efficiency as the natural outcome of a market-driven economy. The renowned economist, Kenneth Arrow (1963), identifies peculiarities of the medical care industry and suggests that it should not be analyzed in the same manner as other markets or industries are. Reinhardt (2001) makes reference to the efficiency of health care delivery in the United States over the years, and suggests that it has improved between 1977 and 1988. Also noteworthy, is the fact that an efficient allocation of resources may not necessarily mean an equitable distribution of resources, as denoted by Greenberg (1988).

\section{References}

1. Anderson, Gerald F.; Uwe Reinhardt; Peter Hussey; and Varduhi Petrosyan, "It's the prices, stupid: Why the United States is so different from other countries," Health Affairs, Vol. 22, No. 3, May/June 2003, p. 86.

2. Anell, Andres, Michael Willis, "International comparison of health care systems using resource profiles," Bulletin of the World Health Organization, Vol. 78, No. 6, 2000, pp.770-778.

3. Arrow, Kenneth J. "Uncertainty and the Welfare Economics of Medical Care," American Economic Review, Vol. 53, No.5, 1963, pp. 941-973.

4. Berger, AN; Brockett, PL; Cooper, WW; and Pastor, JT "New approaches for analyzing and evaluating the performance of financial institutions," European Journal of Operational Research, Vol. 98, 1997, pp. 169174.

5. Bhat, Ramesh "Methodology note: Data Envelopment Analysis (DEA)," Journal of Health Management, Vol. 3, No.2, July-December 2001, pp.309-328.

6. Blendon, Robert J.; C. Schoen; C. DesRoches, R. Osborn, and Kinga Zapert; "Common concerns amid diverse systems: Health care experience in five countries," Health Affairs, Vol. 22, No. 3, May/June 2003, p. 106.

7. Brown, Lawrence D., "Comparing health systems in four countries: Lessons for the United States," American Journal of Public Health, Vol. 93, No.1, January 2003, pp.52-57.

8. Charnes, A; Cooper, WW; Rhodes, E. "Measuring the efficiency of decision making units," European Journal of Operational Research, Vol. 2, 1978, pp. 429-444.

9. Cherchye, Laurens "Using data envelopment analysis to assess macroeconomic policy performance," Applied Economics, Vol. 33, 2001, pp.407-416.

10. Cooper, W.W.; L. M. Seiford; and Kaoru Tone, Data Envelopment Analysis: A comprehensive text with models, applications, references and DEA-solver software, Kluwer Academic Publishers, Boston/Dorecht/London, 2000.

11. Dimelis, Sophia and Maria Dimopoulou, "Evaluating productivity growth measures in EU," Economics of Planning: 2002, Vol.35, No. 2, 2002, pp.161-181. 
12. Evans, David B.; Ajay Tandon; Christopher Murray; and Jeremy Lauer, "Comparative efficiency of national health systems: cross national econometric analysis," BMJ, Vol. 323, 11, August 2001, pp. 307-310.

13. Farrell, M.J. "The measurement of productive efficiency," Journal of Royal Statistical Society, Vol. 120, A, 1957, pp.253-281.

14. Greenberg, Warren, “Introduction," Journal of Health Policy, Politics and Law, Vol. 13, No.2, 1988, pp.223224.

15. Hollingsworth, Bruce; P.J. Dawson; and N. Maniakadis "Efficiency measurement of health care: a review of non-parametric methods and applications," Health Care Management Science, Vol.2, 1999, pp.161-172.

16. Giokas, D. "The use of goal programming, regression analysis and data envelopment analysis for estimating efficient marginal costs of hospitals," Journal of Multicriteria Decision Analysis, Vol. 11, Jul-Oct. 2002, pp. 261-268.

17. Giuffrida, Antonio, and Hugh Gravelle, "Measuring performance in primary care: econometric analysis and DEA,” Applied Economics, Vol. 33, 2001, pp.163-175.

18. Hofmarcher, Maria M.; Iain Paterson; and Monika Riedel, "Measuring hospital efficiency in Austria - a DEA approach," Health Care Management Science, Vol. 5, No1, February 2002, pp. 7-14.

19. Nyhan, Ronald C., and Peter Cruise "Comparative performance assessment in managed care: Data envelopment analysis for health care managers," Managed Care Quarterly, Vol. 8, No. 1, 2000, pp. 18-27.

20. Reinhardt, Uwe E. "Can efficiency in health care be left to the market?" Journal of Health Policy, Politics and Law, Vol. 26, No.5, 2001, pp. 967-992.

21. Seiford, LM "Data Envelopment Analysis: The evaluation of the state of the art (1978-1985)," The Journal of Productivity Analysis, Vol. 7, 1996, pp.99-137.

22. Smith, P. "Model misspecification in Data Envelopment Analysis," Annals of Operation Research, Vol.73, 1997, pp. 233-252.

23. Thanassoulis, Emmanuel, Introduction to the theory and application of Data Envelopment Analysis: A foundation text with integrated software, Kluwer Academic Publishers, Boston/Dorecht/London, 2001.

\section{Appendix A}

Data Sources:

OECD Annual Report, 2000.

Life Expectancies:

http://www.eurohealth.ie/newrep/demograph.htm,

http://www.photius.com/wfb1999/rankings/life_expectancy_mf_1.html, and http://www.infoplease.com/cgi-

bin/id/A0005148.html;

Infant Mortality:

http://www.photius.com/wfb1997/canada/canada_people.html,

http://www.photius.com/wfb1997/united_states/united_states_people.html;

In-patient beds and Physicians, 1999:

http://www.oecdwash.org/DATA/STATS/oecdinfig2002.pdf;

School Life Expectancy:

http://devdata.worldbank.org/edstats/query/ 